\title{
Trajectories of vital status parameters and risk of mortality among acute organophosphorus poisoning patients - a latent class growth analysis
}

\author{
Waqas Ahmed Farooqui ${ }^{1,2^{*}}$ (D) Mudassir Uddin ${ }^{1}$, Rashid Qadeer $^{3}$ and Kashif Shafique 2,4
}

\begin{abstract}
Background: Acute organophosphorus (OP) poisoning is one of the major causes of mortality among patients presenting to emergency departments in developing countries. Although various predictors of mortality among OP poisoning patients have been identified, the role of repeated measurements of vital signs in determining the risk of mortality is not yet clear.

Therefore, the present study examined the relationship between trajectories of vital signs and mortality among OP poisoning patients using latent class growth analysis (LCGA).

Methods: This was a retrospective cohort study using data for 449 OP poisoning patients admitted to Civil-Hospital Karachi from Aug'10 to Sep'16. Demographic data and vital signs, including body temperature, blood pressure, heart rate, respiratory rate, and partial-oxygen pressure, were retrieved from medical records. The trajectories of vital signs were formed using LCGA, and these trajectories were applied as independent variables to determine the risk of mortality using Cox-proportional hazards models. P-values of $<0.05$ were considered statistically significant.

Results: Data for 449 patients, with a mean age of 25.4 years (range 13-85 years), were included. Overall mortality was $13.4 \%(n=60)$. In trajectory analysis, a low-declining systolic blood pressure, high-declining heart rate trajectory, high-remitting respiratory rate trajectory and normal-remitting partial-oxygen pressure trajectory resulted in the greatest mortality, i.e. 38.9,40.0,50.0, and 60.0\%, respectively, compared with other trajectories of the same parameters. Based on multivariable analysis, patients with low-declining systolic blood pressure were three times [HR:3.0,95\%Cl:1.2-7.1] more likely to die compared with those who had a normal-stable systolic blood pressure. Moreover, patients with a high-declining heart rate were three times [HR:3.0,95\%Cl:1.5-6.2] more likely to die compared with those who had a high-stable heart rate. Patients with a high-remitting respiratory rate were six times [HR:5.7,95\%Cl:1.3-23.8] more likely to die than those with a high-stable respiratory rate. Patients with normalremitting partial oxygen pressure were five times [HR:4.7,95\% Cl:1.4-15.1] more likely to die compared with those who had a normal-stable partial-oxygen pressure.

(Continued on next page)
\end{abstract}

\footnotetext{
* Correspondence: waqasahmed.farooqui@gmail.com

'Department of Statistics, University of Karachi, Karachi, Pakistan

${ }^{2}$ School of Public Health, Dow University of Health Sciences, Karachi, Pakistan

Full list of author information is available at the end of the article
}

(c) The Author(s). 2020 Open Access This article is licensed under a Creative Commons Attribution 4.0 International License, which permits use, sharing, adaptation, distribution and reproduction in any medium or format, as long as you give appropriate credit to the original author(s) and the source, provide a link to the Creative Commons licence, and indicate if changes were made. The images or other third party material in this article are included in the article's Creative Commons licence, unless indicated otherwise in a credit line to the material. If material is not included in the article's Creative Commons licence and your intended use is not permitted by statutory regulation or exceeds the permitted use, you will need to obtain permission directly from the copyright holder. To view a copy of this licence, visit http://creativecommons.org/licenses/by/4.0/ The Creative Commons Public Domain Dedication waiver (http://creativecommons.org/publicdomain/zero/1.0/) applies to the data made available in this article, unless otherwise stated in a credit line to the data. 
(Continued from previous page)

Conclusion: The trajectories of systolic blood pressure, heart rate, respiratory rate and partial-oxygen pressure were significantly associated with an increased risk of mortality among OP poisoning patients.

Keywords: Latent growth curve, OP poisoning, Vital signs, Repeated measures

\section{Background}

Acute organophosphorus (OP) poisoning is a global public health challenge. Acute OP poisoning cases have high morbidity and mortality, constituting a challenge for hospital practitioners [1, 2]. A systematic review including data from 102 countries showed that the proportion of suicides due to pesticide self-poisoning varies considerably between regions, from $0.9 \%$ in low- and middle-income countries in the European region to $48.3 \%$ in low- and middle-income countries in the Western Pacific region [3]. In neighbouring countries, the prevalence of OP poisoning among other types of poisoning varies from 7.7 to $20.7 \%$ (20.7\% in China [4], $7.7 \%$ in Iran [5], and $20.7 \%$ in India [6]). Among OP poisoning cases, the case fatality rate varies from 10 to $30 \%$ in developing countries $[7,8]$. In our urban city, the prevalence of OP poisoning among all poisoning cases is reported to be nearly $46.1 \%$, with a mortality rate of $2.7 \%$ [9].

Mortality among patients with acute OP poisoning is considerably high but varies between regions and depends on the quality of healthcare services available to patients. Several other factors, including age, sex, type of poison ingested and its biochemical properties, quantity of poison, time since ingestion, any pre-existing comorbidities and access to health services, influence the outcome of OP poisoning patients [10-14]. The prognosis of acute poisoning depends on the exposure to the toxin as well as the amount of toxin ingested and the physiology of compensation. In our country, it is difficult to judge the amount because patients ingest different brands, and there is a lack of description of the concentration of the poisonous substance $[9,15]$. In clinical settings, the prognosis of these patients is mainly assessed by vital status, including body temperature, blood pressure, heart rate and respiratory rate, levels of anticholinesterases, oxygenation and $\mathrm{PaCO}_{2}$ for hypoventilation requiring intubation/ventilation. Vital signs play an important role in the diagnosis of intoxicated patients since they are the key components of toxic syndrome. However, their role in assessing the severity of poisoning and prognosis of these patients remains unclear [16].

One-third of all OP poisoning patients also require mechanical ventilation (MV) due to heavy ingestion, the toxicity of the poison ingested and delayed presentation at the hospital [17-19], and among OP poisoning patients on MV, low pseudocholinesterase (PChE), high creatinine (Cr), low Glasgow Coma Scale (GCS) score and long hospitalization durations are all linked with high mortality [10-12, 17].

Many scoring systems are currently being used to evaluate the severity of acute OP poisoning, such as the Acute Physiology and Chronic Health Evaluation (APAC HE) II score [20, 21], GCS, Peradeniya Organophosphorus Poisoning Scale (POPS) [22], Poisoning Severity Score (PSS) [23, 24], Sequential Organ Failure Assessment (SOFA) [25], Simplified Acute Physiology Score II (SAPS II) [26], and Practical Predicting Scoring System [4]. These scoring systems are complex and rely on subjective assessment of clinical information and laboratory investigations, which are difficult to acquire or accurately describe.

Several studies have assessed the role of vital status parameters in OP poisoning patient prognosis, though the findings are inconclusive to date $[17,27,28]$. One of the main reasons might be the conventional approach in many studies of using a single baseline measurement of vital status parameters to predict mortality. These parameters are dynamic and tend to change substantially and sometimes quite rapidly. In such a scenario, the approach of linking single measurements at the time of presentation with mortality during follow-up might not be an appropriate method. In such studies in which vital status parameters and laboratory investigations are observed at baseline only, an important question is whether the mean level of a parameter changes over time; if it does, it should be determined whether that change leads to certain latent groups that are different than the classifications made based on single baseline measurement of the same variable. Accordingly, this single observation approach might be prone to misclassification bias.

In general, latent class growth analysis (LCGA) provides a better alternative to observe and estimate growth trajectories over time for dynamic variables. Structural equation modelling (SEM) advances basic longitudinal analysis of data to include latent variable growth over time while modelling both individual and group changes using slopes and intercepts [29]. The traditional techniques employed are analysis of variance, multiple regression and multilevel models, which are variablecentred approaches; in contrast, LCGA is a personcentred approach focused on identifying unobserved subpopulations comprising similar individuals [30]. To the best of our knowledge, no previous study has 
assessed the latent trajectories of vital status parameters in OP poisoning patients and their relationship with mortality. Therefore, the aim of the present study was to analyse the growth trajectory of vital status parameters among OP poisoning patients using LCGA and determine relationships between classes of individuals based on individual response (vital parameters) patterns with mortality using survival analysis.

\section{Methods}

This was a retrospective cohort of OP poisoning patients older than 13 years. All patients admitted from August 2010 to September 2016 at the medical intensive care unit (ICU) of a tertiary care hospital, Dr. Ruth K.M. Pfau/Civil Hospital Karachi, Pakistan, were included in this study. A total of 499 OP poisoning patients (of either sex) confirmed based on medical records were eligible during the six-month data collection period from June 2016 to November 2016. Dr. Ruth K. M Pfau/Civil Hospital Karachi is one of the largest tertiary care hospitals in the province of Sindh, Pakistan, with an annual patient turnover of approximately $>4,000,000$.

\section{Study variables}

Data for each patient were obtained from medical records, including demographics (age, sex), elapsed time since poison ingestion, and ICU stay. In addition to these parameters, vital status parameters (body temperature, systolic blood pressure, diastolic blood pressure, heart rate, respiratory rate and partial oxygen pressure) were obtained from medical records for an initial period of 2 days as per the completion of medical records. These vital status parameters were captured over time during the hospital stay as repeated measures in this study. In-hospital mortality data were recorded to assess the outcome of patients during the hospital stay.

\section{Latent classes}

LCGA was used to detect trajectories of vitals over time. This falls under the umbrella of finite mixture modelling and is designed to detect latent classes over time of individuals following comparable movements of a determinant [31] . Our models used first- and second-order polynomials. Initially, data files were created for each of the vital status parameters and for each order. Per guidelines [32], models were prepared separately for each order, vital sign, and class (two/three/four). For every individual, we computed posterior probabilities for each trajectory by running all models. Latent classes extracted from the output files were created. Classes were later transformed in STATA with other demographic and vital status parameters. We approximated the trajectories by best-fitting based on the minimum Akaike Information Criterion (AIC), Bayesian Information Criterion
(BIC) and high log likelihood [33]. These indices are suggestive of linear models compared to quadratic models for any class.

Our models used first- and second-order polynomials that best fit indices to find the maximum latent classes. The first-order polynomials exhibited a linear growth pattern when using data for 449 patients, which required at least three repeated observations. However, secondorder polynomials revealed quadratic growth patterns required at least four repeated observations, with all four observations for only 424 patients. For all parameters based on fit indices, we found the best number of classes using first-order polynomials; an exception was temperature, for which we identified best classes using second-order polynomials.

\section{Statistical analysis}

The data were entered and managed using Microsoft Office 365 Excel. Latent classes were generated from MPlus software, and inferential analysis and figures were plotted using STATA software version 15. Baseline differences among deceased and alive individuals were assessed. To detect differences in age, total ICU stay and vital status parameters between deceased and alive individuals, associations of mortality with sex were assessed using the Wilcoxon rank sum test based on data distribution.

For survival analysis, total ICU stay time was used to define risk time. We computed unadjusted and adjusted hazard ratios and respective confidence intervals for mortality by the assigned trajectory using the Cox proportional hazards models reported in Table 2. In multivariable analysis, we adjusted for age and approximate time elapsed since poison ingestion. We evaluated proportional hazards assumption by the phtest and smoothed Schoenfeld residuals plotted against time; the assumption was identified as satisfactory and not violated [34]. $P$-values $<0.05$ were considered statistically significant.

\section{Ethical review}

The study was approved by the Institutional Review Board of Dow University of Health Sciences (DUHS) (Ref No. IRB-560/DUHS/Approval/2015/75 dated 11th Jun 2015) and Board of Advanced Studies and Research (BASR) (BASR/No./02505/Sc. dated $2^{\text {nd }}$ October 2015) of the University of Karachi-Pakistan.

\section{Results}

Of 499 patients, records for 19 were excluded: 13 due to incomplete data; 2 due to incorrect registration; and 4 due to a self-reported history of chronic conditions such as hypertension, diabetes mellitus, osteoarthritis, asthma or pregnant women. Another 31 patients were excluded 
due to an ICU stay of less than $36 \mathrm{~h}$, of whom 11 died. Thus, data for 449 patients, with a mean age of cohort 25.4 years (range 13-85 years), were included in the final analysis. The overall mortality was $13.4 \%(n=60)$. Age and elapsed time since ingestion of poison were significantly higher among deceased compared to alive individuals, whereas sex, total ICU stay, and vital status parameters were not significantly different. (Table 1).

We assigned labels to the trajectories based on their modelled graphic patterns (Figs. 1 and 2). We defined the first part of labels based on the start of vital sign ranges [35-39] (e.g., low, high, normal) and the second part on their repeated measure patterns (e.g., consistent, stable, declining, increasing, remitting (up then down or vice versa)). Word remitting refers to a pattern of multiple repetitions of low and high observations starting from low to high or vice versa. The "decreasing" designation used for other variables was applied for patients who had initially high values of a given variable, which then decreased during the course of observations; $36 \mathrm{~h}$ and "increasing" was used for patients who had initially low values, which then reduced the ICU stay by $36 \mathrm{~h}$. Based on the mean intercept and slope of individual patterns, we identified two distinct trajectories (high-stable and high-declining) of heart rate in the 449 patients (mortality in high-stable was $50 / 424=11.8 \%$; mortality in high-declining was 10/25 =40.0\%). (Fig. 1).

Three trajectories (high-declining, normal-stable, and low-declining) were identified for systolic blood pressure. Mortality for high-declining patients was $8 / 53=$ $15.1 \%$; it was $45 / 378=11.9 \%$ for normal-stable patients and $7 / 18=38.9 \%$ for low-declining patients. (Fig. 1).
Two trajectories (high-stable and high-remitting) were identified for respiratory rate. The mortality for the high-stable group was $58 / 445=15.1 \%$, and that for the high-remitting group was $02 / 04=50.0 \%$. (Fig. 2).

Two trajectories (normal-stable and normal-remitting) were also identified for partial oxygen pressure. The mortality for normal-stable patients and normalremitting patients was $57 / 444=12.8 \%$ and $03 / 05=$ $60.0 \%$, respectively. (Fig. 2).

According to multivariable analysis after adjustment for age and elapsed time, patients with low-declining systolic blood pressure were three times more likely [HR: $3.0,95 \%$ CI: $1.2-7.1, P$-value $=0.014$ ] to die compared with those who had a normal-stable systolic blood pressure and those in the high-declining heart rate trajectory were three times [HR: 3.0, 95\% CI: 1.5-6.2, Pvalue $=0.002]$ more likely to die compared with those who had a high-stable heart rate. Patients in a highremitting respiratory rate trajectory were six times [HR: 5.7, 95\% CI: $1.3-23.8, P$-value $=0.018]$ more likely to die compared with those who had a high-stable respiratory rate. Patients in the normal-remitting partial oxygen pressure trajectory were five times [HR: 4.7, 95\% CI: 1.4-15.1, $P$-value $=0.010]$ more likely to die compared with those who had a normal-stable partial oxygen pressure. (Table 2).

\section{Discussion}

\section{Summary of findings}

Among OP poisoning cases, older age and longer elapsed time since ingestion were significantly associated with mortality. Furthermore, individuals in the lowdeclining systolic blood pressure trajectory and high-

Table 1 Descriptive statistics (median (IQR)) of baseline characteristics with mortality

\begin{tabular}{|c|c|c|c|}
\hline Basic Characteristics & Alive & Dead & $P$-value \\
\hline Linear Classes (3 OR 4 Time Points), $N=449$ & 389 & 60 & \\
\hline Quadratic Classes (4 Time Points), $N=424$ & 370 & 54 & \\
\hline \multicolumn{4}{|l|}{ Sex } \\
\hline Female $(N=236, \%)$ & $206(87.3)$ & $30(12.7)$ & \multirow[t]{2}{*}{$0.669^{a}$} \\
\hline Male $(N=213, \%)$ & $183(85.9)$ & $30(14.1)$ & \\
\hline Age (years) & $22.0(18.0-28.0)$ & $28.0(20.0-37.5)$ & $0.0002^{b}$ \\
\hline Elapsed Time (hours) & $4.4(1.7-7.6)$ & $8.5(6.7-12.1)$ & $<0.001^{\mathrm{b}}$ \\
\hline ICU Stay (hours) & $111.0(74.8-228.0)$ & $164.6(78.0-245.0)$ & $0.445^{b}$ \\
\hline Temperature $\left({ }^{\circ} \mathrm{F}\right)$ & $98.5(98.0-99.0)$ & $98.5(98.0-99.0)$ & $0.333^{b}$ \\
\hline SBP $(\mathrm{mmHg})$ & $120.0(100.0-130.0)$ & $115.0(100.0-140.0)$ & $0.510^{b}$ \\
\hline $\mathrm{DBP}(\mathrm{mmHg})$ & $70.0(60.0-80.0)$ & $70.0(60.0-90.0)$ & $0.366^{b}$ \\
\hline Heart rate (minutes) & $110.0(90.0-125.0)$ & $111.0(86.0-134.0)$ & $0.496^{\mathrm{b}}$ \\
\hline Respiratory rate (minutes) & $22.0(20.0-24.0)$ & $20.0(18.0-24.0)$ & $0.360^{b}$ \\
\hline $\mathrm{PO}_{2}(\mathrm{mmHg})$ & $99.0(98.0-99.0)$ & $99.0(97.0-99.0)$ & $0.097^{b}$ \\
\hline
\end{tabular}

$I Q R$ interquartile range (25th-75th percentile), $P_{2}$ partial oxygen pressure, ${ }^{a}$ chi-square test, ${ }^{b}$ Wilcoxon rank sum test, $I C U$ intensive care unit, $S B P$ systolic blood pressure, DBP diastolic blood pressure 

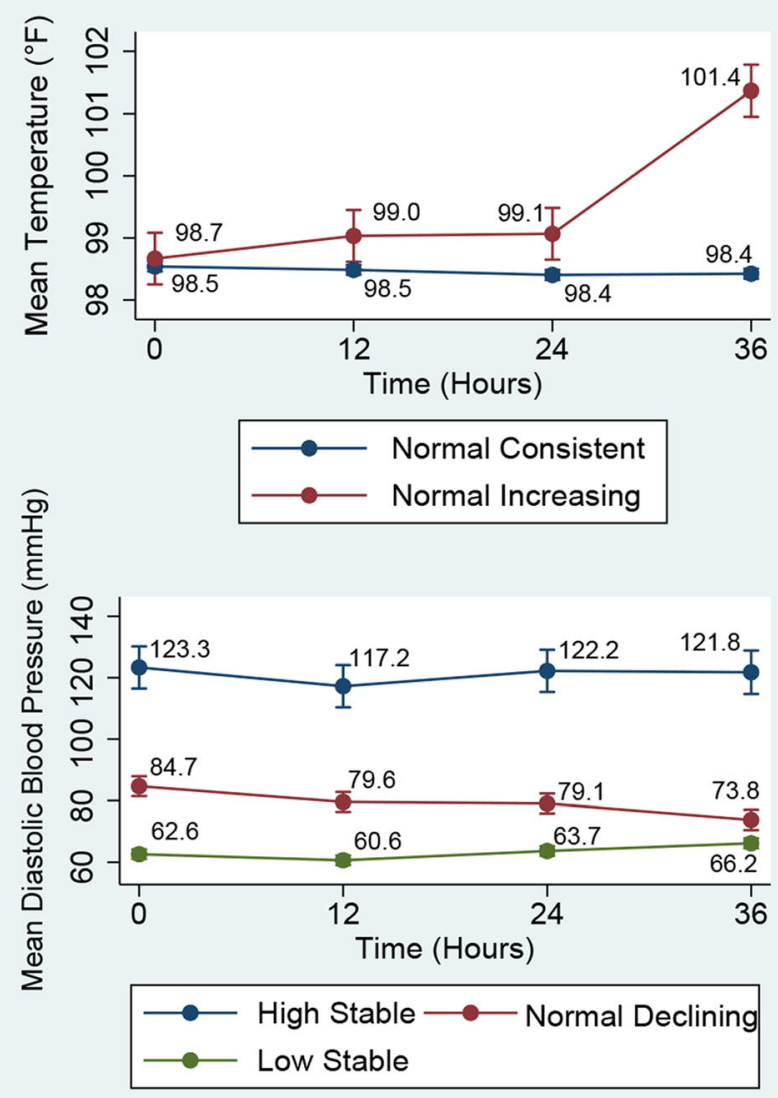
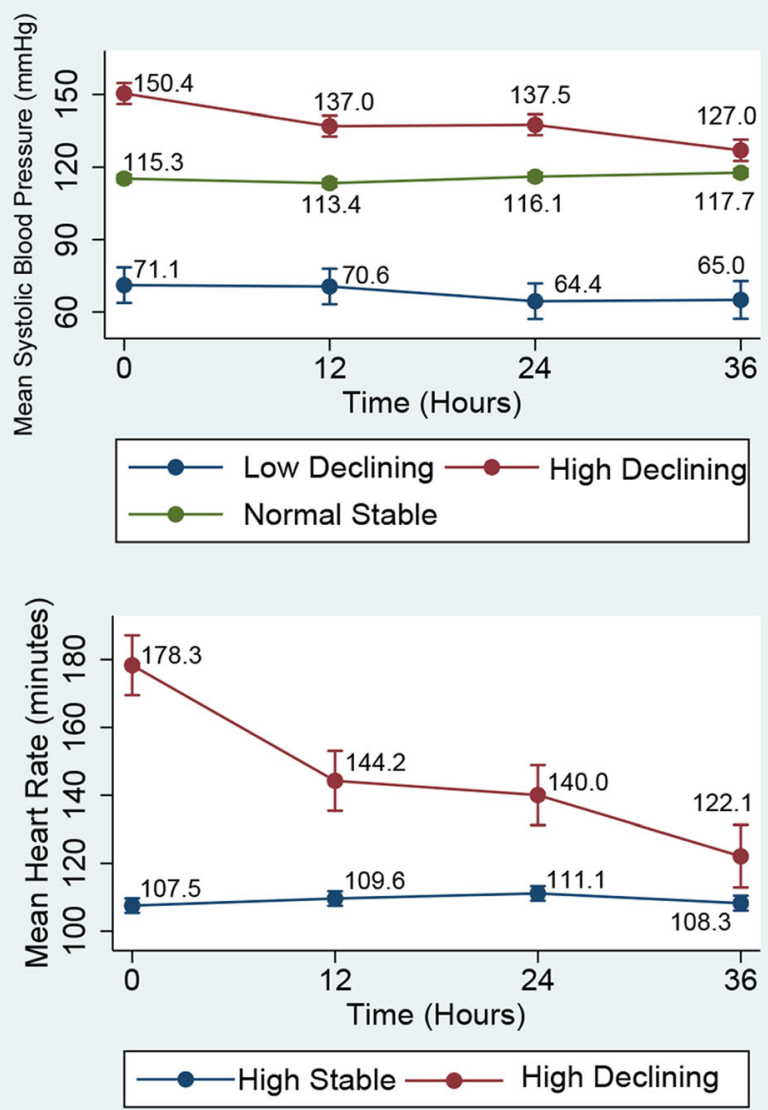

Fig. 1 Trajectories of vital signs (temperature, SBP, DBP, heart rate)

declining heart rate trajectory had significantly higher mortality than those in the normal-stable systolic blood pressure trajectory and the high-stable heart trajectory. Similarly, patients in the high-remitting respiratory rate trajectory and those in the normal-remitting partial oxygen pressure trajectory had a nearly sixfold and fivefold increased risk of mortality, respectively, compared with those who were in the high-stable respiratory rate and normal-stable partial oxygen pressure categories. These findings suggest that routine clinical parameters, if observed repeatedly, might be useful clinical tools to identify high-risk groups of patients who might experience considerably high mortality. The mortality in our study is comparable to previously published papers on OP poisoning from different regions, including neighbouring countries $[4,9,18,27,40-42]$; however, our study appeared to show higher (13.4\%) mortality compared to a published paper (4.11\%) [42] from another tertiary care setting in our metropolitan city. Although the average ages of patients in their study and our study were comparable, a significantly higher percentage of women (73\%) was enrolled in the previously published study
[42] than in our study (52.5\%). Therefore, the low mortality in the previous study might be explained by a high percentage of women because it is well known now that the risk of mortality and success of suicidal attempts due to poisoning among females tends to be lower than that of men [43-46]. Second, in the previous study, patients were kept in the general medical ward for treatment, suggesting that the poisoning cases were mild to moderate. However, in our cohort, the patients all has been directly transferred from emergency to intensive care units, which reflects predominantly more severe forms of poisoning cases with deteriorating clinical condition and explains the high mortality in our study compared to the previous study. Older age and longer time elapsed since ingestion of poison were significant predictors of mortality in our series, and the findings are quite consistent with previously published studies [18, 27, 42].

Trajectory analysis showed low-declining systolic blood pressure and high-declining heart rate to be significantly associated with an increased risk of mortality among OP poisoning patients. The result for SBP was in contrast with multiple studies showing that it was not 

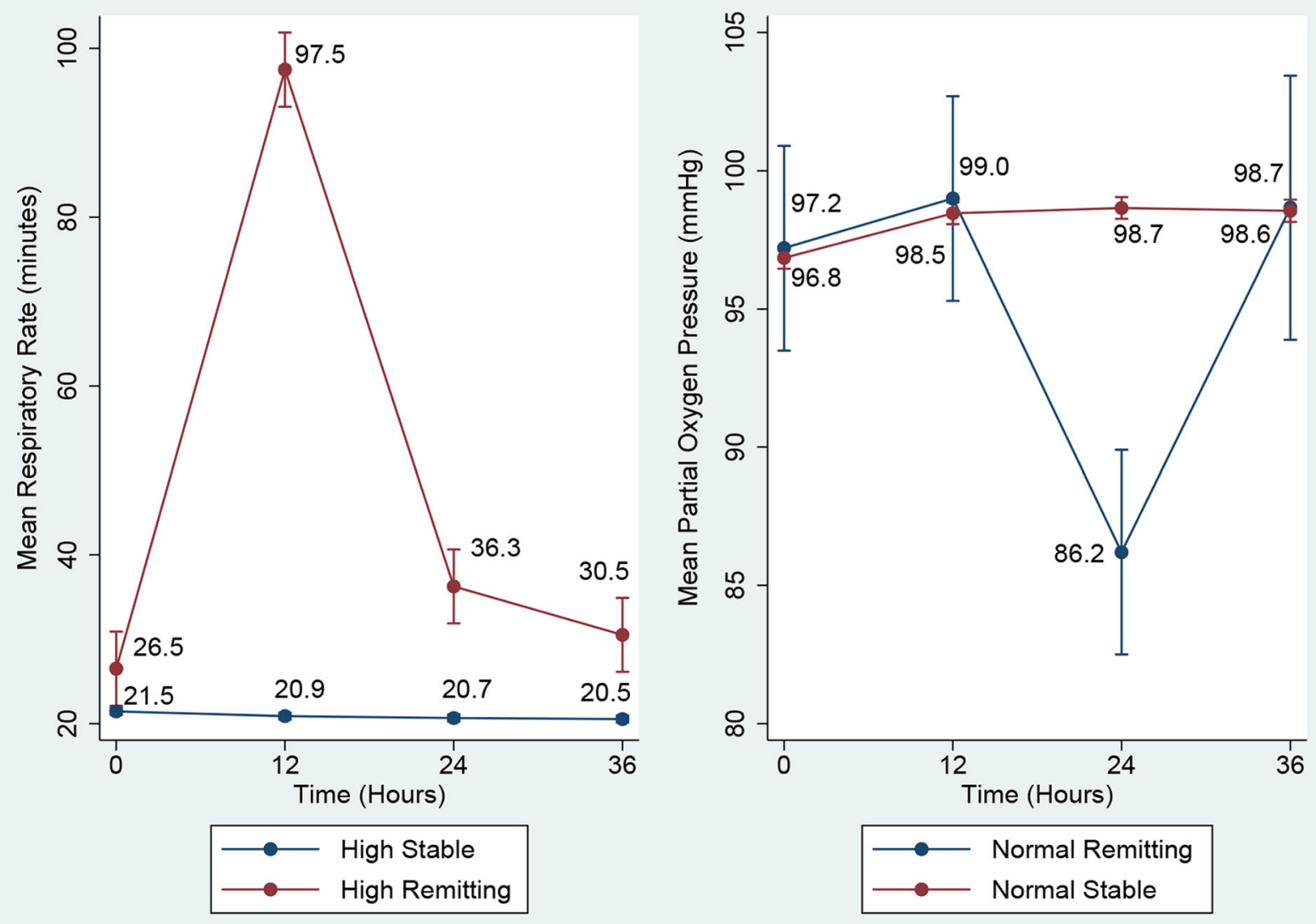

Fig. 2 Trajectories of vital signs (respiratory rate, partial oxygen pressure)

associated with mortality $[26,27,42]$. The heart rate result was somewhat supported by European and Asian studies, which reported that a high heart rate is associated with mortality [27, 42, 47]; nonethelesss, it was not linked with mortality in two Asian studies [48, 49]. Trajectories of body temperature and diastolic blood pressure did not show any significant relationship with mortality. LCGA in our study indicated that the highremitting trajectory of respiratory rate was linked to mortality. However, these results were in contrast with previous studies, as high temperature and low respiratory rate have exhibited significance with mortality in multiple studies [26, 47, 49, 50], though nonsignificance for respiratory rate [47] and temperature [48] was observed in a study of OP poisoning patients. Multiple studies have investigated vital signs but not $\mathrm{PO}_{2}[47,50$, 51], whereas our study showed that a normal-remitting partial oxygen pressure trajectory is linked to an increased risk of mortality.

Vital status parameters and their relationship with mortality among OP poisoning patients were not entirely clear in previous studies $[19,42,52]$. One reported that
OP poisoning patients had a normal temperature at the time of admission but that their mean tympanic temperature increased considerably after atropine administration during the hospital stay until $72 \mathrm{~h}$ after admission [53] . Moreover, previous studies only included baseline measurements of vital status parameters and examined their relationship with mortality. Our study is unique in that it accounted for multiple observations of vital status parameters in the first $36 \mathrm{~h}$ after poisoning and linked them to mortality. Our approach is also closer to real life scenarios, in which such OP poisoning patients display varying levels of these parameters; therefore, our findings may be more applicable to clinical settings.

Commonly used scoring systems heavily depend on clinical and laboratory investigational information [4, 20-26] Furthermore, most scoring systems rely on single measurements, usually at the time of patient admission. The LCGA used in this study is a person-centred approach in which latent classes identify trajectories of patients based on repeated measures of very routine clinical parameters [54] . Individuals are similar within 
Table 2 Relationship of mortality with vitamin status parameters = latent class growth analysis

\begin{tabular}{|c|c|c|c|c|c|c|}
\hline Vital Parameters & $\begin{array}{l}\text { Alive } \\
(N=389)\end{array}$ & $\begin{array}{l}\text { Dead } \\
(N=60)\end{array}$ & Total & $P$-value & $\begin{array}{l}\text { Unadjusted HR } \\
\text { (95\% C.I) }\end{array}$ & $\begin{array}{l}\text { Adjusted HR } \\
\text { (95\% C.I) }\end{array}$ \\
\hline Temperature & $N=370$ & $N=54$ & & & & \\
\hline Normal consistent & 359 (87.8\%) & $50(12.2 \%)$ & 409 & $0.110^{\mathrm{b}}$ & 1.0 & 1.0 \\
\hline Normal increasing & $11(73.3 \%)$ & $4(26.7 \%)$ & 15 & & $1.9(0.7,5.5)$ & $2.0(0.7,5.7)$ \\
\hline \multicolumn{7}{|l|}{ SBP } \\
\hline Normal stable & $333(88.1 \%)$ & 45 (11.9\%) & 378 & $0.004^{a}$ & 1.0 & 1.0 \\
\hline High declining & 45 (84.9\%) & $8(15.1 \%)$ & 53 & & $1.0(0.5,2.1)$ & $0.8(0.3,1.7)$ \\
\hline Low declining & $11(61.1 \%)$ & 7 (38.9\%) & 18 & & $3.0(1.4,6.7)$ & $3.0(1.2,7.1)$ \\
\hline \multicolumn{7}{|l|}{ DBP } \\
\hline Normal declining & $68(82.9 \%)$ & $14(17.1 \%)$ & 82 & $0.256^{\mathrm{a}}$ & 1.0 & 1.0 \\
\hline High stable & $14(77.8 \%)$ & $4(22.2 \%)$ & 18 & & $1.3(0.4,3.9)$ & $1.5(0.5,4.8)$ \\
\hline Low stable & 307 (88.0\%) & $42(12.3 \%)$ & 349 & & $0.8(0.5,1.5)$ & $1.0(0.5,1.8)$ \\
\hline \multicolumn{7}{|l|}{ Heart Rate } \\
\hline High stable & $374(88.2 \%)$ & $50(11.8 \%)$ & 424 & $0.001^{\mathrm{b}}$ & 1.0 & 1.0 \\
\hline High declining & $15(60.0 \%)$ & $10(40.0 \%)$ & 25 & & $2.7(1.4,5.4)$ & $3.0(1.5,6.2)$ \\
\hline \multicolumn{7}{|l|}{ Respiratory Rate } \\
\hline High stable & $387(87.0 \%)$ & $58(13.0 \%)$ & 445 & $0.088^{\mathrm{b}}$ & 1.0 & 1.0 \\
\hline High remitting & $2(50.0 \%)$ & $2(50.0 \%)$ & 4 & & $3.8(0.9,15.5)$ & $5.7(1.3,23.8)$ \\
\hline \multicolumn{7}{|l|}{$\mathrm{PO}_{2}$} \\
\hline Normal Stable & $387(87.2 \%)$ & $57(12.8 \%)$ & 444 & & 1.0 & 1.0 \\
\hline Normal Remitting & $2(40.0 \%)$ & $3(60.0 \%)$ & 5 & $0.019^{b}$ & $4.9(1.5,15.9)$ & $4.7(1.4,15.1)$ \\
\hline
\end{tabular}

Adjusted covariate: age \& elapsed time; ${ }^{a}$ Chi-square test; ${ }^{\mathrm{b}}$ Fisher exact test; $S B P$ systolic blood pressure, $D B P$ diastolic blood pressure, $P O_{2}$ partial oxygen pressure, $H R$ hazard ratio

classes but differ across them [30]. Trajectories of routine clinical parameters are much more useful and handier for clinical utility and decision making than other lab-based investigations used in different scoring systems.

\section{Strength and weakness}

This study has several strengths and limitations, which should be considered when drawing any conclusions. This study was unique because multiple observations of vital status parameters in the first $36 \mathrm{~h}$ of admission into intensive care were made and its relationship with mortality among OP poisoning patients was determined. To the best of our knowledge, this is the first study to assess the relationship of vital status parameters with mortality using latent class growth analysis. The current study had a reasonable sample size by including data from several years from the intensive care unit of a tertiary care hospital, which provides generalizable results in our context.

In terms of weaknesses, the amount of poison ingested was obtained from medical records, which might not have been correctly estimated by the clinicians. There is some evidence that suggests that the difference in the type of insecticide ingested can influence the outcome $[23,55]$. As in the majority of the cases in our cohort, we could not ascertain the type of poison ingested, which might also have some influence on mortality between different trajectories. This remains a limitation of our study. Another important point is the retrospective design of the study, which might have compromised the quality of the data to some extent. Nevertheless, our retrospective study provides the first application of trajectory analysis to predicting mortality among OP poisoning patients. Established biomarkers such as anticholinesterases, malondialdehyde, and glutathione were not included in our analysis because the repeated measures of these markers were not available in medical records for trajectory analysis. However, this study examined accessible, noninvasive, inexpensive vital status parameters that have more clinical utility and are much more convenient than laboratory-based markers.

\section{Conclusion}

Latent classes of systolic blood pressure, heart rate, respiratory rate and partial oxygen pressure were significant predictors of mortality among acute OP poisoning patients. Large-scale studies with the addition of biomarkers are needed to determine the clinical utility of these trajectories of vital status parameters in determining the prognosis of patients with acute OP poisoning. 


\section{Abbreviations}

OP: Organophosphorus; LCGA: Latent class growth analysis; ICU: Intensive care unit; GCS: Glasgow Coma Scale; AIC: Akaike information criteria; BIC: Bayesian information criteria; HR: Hazard ratio; SBP: Systolic blood pressure; DBP: Diastolic blood pressure; SEM: Structural equation models; MV: Mechanical ventilation

\section{Acknowledgements}

We thank Marium, Farah, Mahrukh \& Arsalan for helping in data compilation; Dr. Javed labal for proposal \& Dr. Arafat for scientific comments.

\section{Authors' contributions}

KS and WAF conceived the idea, draft of manuscript and result interpretation, RQ provided clinical perspective, provided access to data, MU helped in literature review, modeling and referencing, WAF performed compilation, transformation, and statistical analysis. All authors read and approved the final manuscript.

\section{Funding}

No funding was obtained for this study.

\section{Availability of data and materials}

Data included in the current study are not publicly available to ensure confidentiality of the patients but are available from the corresponding author on reasonable request.

\section{Ethics approval and consent to participate}

The study was approved by the Institutional Review Board of Dow University of Health Sciences (DUHS) since teaching Hospital Civil is affiliated with DUHS. The consent form was not applicable as the study design was retrospective.

\section{Consent for publication}

Not applicable.

\section{Competing interests}

The authors declare that they have no competing interests.

\section{Author details}

${ }^{1}$ Department of Statistics, University of Karachi, Karachi, Pakistan. ${ }^{2}$ School of Public Health, Dow University of Health Sciences, Karachi, Pakistan. ${ }^{3}$ Department of Medicine, Dr. Ruth K.M. Pfau/Civil Hospital Karachi, Dow University of Health Sciences, Karachi, Pakistan. ${ }^{4}$ Institute of Health and Wellbeing, University of Glasgow, Glasgow, UK.

\section{Received: 20 February 2020 Accepted: 30 September 2020}

\section{Published online: 12 October 2020}

\section{References}

1. Dart RC, Bronstein AC, Spyker DA, Cantilena LR, Seifert SA, Heard SE, et al. Poisoning in the United States: 2012 emergency medicine report of the National Poison Data System. Ann Emerg Med. 2015;65(4):416-22.

2. Krakowiak A, Kotwica M, Śliwkiewicz K, Piekarska-Wijatkowska A. Epidemiology of acute poisonings during 2003-2007 in toxicology unit, department of occupational medicine and toxicology, Nofer Institute of Occupational Medicine, Łódź, Poland. Int J Occup Med Environ Health. 2011;24(2):199-207.

3. Mew EJ, Padmanathan P, Konradsen F, Eddleston M, Chang SS, Phillips MR, et al. The global burden of fatal self-poisoning with pesticides 2006-15: systematic review. J Affect Disord. 2017;219:93-104.

4. Dong N, Liu J, Wang Z, Gao N, Pang L, Xing J. Development of a practical prediction scoring system for severe acute organophosphate poisoning. J Appl Toxicol. 2020;40(7):889-96. https://doi.org/10.1002/jat.3950.

5. Alizadeh AM, Hassanian-Moghaddam H, Shadnia S, Zamani N, Mehrpour O. Simplified acute physiology score II/acute physiology and chronic health evaluation $\|$ and prediction of the mortality and later development of complications in poisoned patients admitted to intensive care unit. Basic Clin Pharmacol Toxicol. 2014;115(3):297-300.

6. Srivastava A, Peshin SS, Kaleekal T, Gupta SK. An epidemiological study of poisoning cases reported to the national poisons information Centre, all
India Institute of Medical Sciences, New Delhi. Hum Exp Toxicol. 2005;24(6): 279-85.

7. Dong H, Weng YB, Zhen GS, Li FJ, Jin AC, Liu J. Clinical emergency treatment of 68 critical patients with severe organophosphorus poisoning and prognosis analysis after rescue. Medicine (Baltimore). 2017;96(25):e7237.

8. Tallat S, Hussien R, Mohamed RH, Abd El Wahab MB, Mahmoud M. Caspases as prognostic markers and mortality predictors in acute organophosphorus poisoning. J Genet Eng Biotechnol. 2020;18(1):10.

9. Amir A, Haleem F, Mahesar G, Sattar RA, Qureshi T, Syed JG, et al. Epidemiological, poisoning characteristics and treatment outcomes of patients admitted to the National Poisoning Control Centre at Karachi, Pakistan: a six month analysis. Cureus. 2019;11(11):1-9. https://doi.org/10. 7759/cureus.6229.

10. Hu YH, Chou HL, Lu WH, Huang HH, Yang CC, Yen DH, et al. Features and prognostic factors for elderly with acute poisoning in the emergency department. J Chin Med Assoc. 2010;73(2):78-87.

11. Strøm J, Thisted B, Krantz T, Sørensen MB. Self-poisoning treated in an ICU: drug pattern, acute mortality and short-term survival. Acta Anaesthesiol Scand. 1986;30(2):148-53.

12. Singh $O$, Javeri $Y$, Juneja D, Gupta $M$, Singh $G$, Dang R. Profile and outcome of patients with acute toxicity admitted in intensive care unit: experiences from a major corporate hospital in urban India. Indian J Anaesth. 2011;55(4): 370-4.

13. Kang EJ, Seok SJ, Lee KH, Gil HW, Yang JO, Lee EY, et al. Factors for determining survival in acute organophosphate poisoning. Korean J Intern Med. 2009;24(4):362-7.

14. Dash SK, Mohanty MK, Mohanty S, Patnaik KK. Organophosphorus poisoning: victim specific analysis of mortality and morbidity. Med Sci Law. 2008;48(3):241-5.

15. Tahir MN, Akbar AH, Naseer R, Khan QO, Khan F, Yaqub I. Suicide and attempted suicide trends in Mianwali, Pakistan: social perspective. East Mediterr Health J. 2014;19(Suppl 3):S111-4.

16. Lee $\mathrm{CH}$, Shih $\mathrm{CP}$, Hsu KH, Hung DZ, Lin CC. The early prognostic factors of glyphosate-surfactant intoxication. Am J Emerg Med. 2008;26(3):275-81.

17. Acikalin A, Disel NR, Matyar S, Sebe A, Kekec Z, Gokel Y, et al. Prognostic factors determining morbidity and mortality in organophosphate poisoning. Pak J Med Sci. 2017;33(3):534-9.

18. Amin DM, Abaza MT, El Azawy DS, Ahmed Al. Morbidity and mortality indicators in acute organophosphate poisoning in Zagazig University Hospital, Egypt: retrospective study. Occup Dis Environ Med. 2018;6(4):13040.

19. Muley A, Shah C, Lakhani J, Bapna M, Mehta J. To identify morbidity and mortality predictors in acute organophosphate poisoning. Indian J Crit Care Med. 2014;18(5):297-300

20. Sam KG, Kondabolu K, Pati D, Kamath A, Pradeep Kumar G, Rao PG Poisoning severity score, APACHE II and GCS: effective clinical indices for estimating severity and predicting outcome of acute organophosphorus and carbamate poisoning. J Forensic Legal Med. 2009;16(5):239-47.

21. Wu X, Xie W, Cheng Y, Guan Q. Severity and prognosis of acute organophosphorus pesticide poisoning are indicated by C-reactive protein and copeptin levels and APACHE II score. Exp Ther Med. 2016;11(3):806-10.

22. Senanayake N, de Silva HJ, Karalliedde L. A scale to assess severity in organophosphorus intoxication: POP scale. Hum Exp Toxicol. 1993;12(4): 297-9.

23. Davies JO, Eddleston M, Buckley NA. Predicting outcome in acute organophosphorus poisoning with a poison severity score or the Glasgow coma scale. QJM. 2008;101(5):371-9.

24. Persson HE, Sjoberg GK, Haines JA. Pronczuk de Garbino J. poisoning severity score. Grading of acute poisoning. J Toxicol Clin Toxicol. 1998;36(3): 205-13.

25. Mohamed S, Hasb Elnabi M, Moussa M, Tawfik H, Adly M. The accuracy comparison of scoring Systems in the Outcome Prediction of acute organophosphate poisoning. Ain Shams J Forensic Med Clin Toxicol. 2019; 33(2):8-15.

26. Kim YH, Yeo JH, Kang MJ, Lee JH, Cho KW, Hwang S, et al. Performance assessment of the SOFA, APACHE II scoring system, and SAPS II in intensive care unit organophosphate poisoned patients. J Korean Med Sci. 2013; 28(12):1822-6.

27. Gunduz E, Dursun R, Icer M, Zengin Y, Gullu MN, Durgun HM, et al. Factors affecting mortality in patients with organophosphate poisoning. J Pak Med Assoc. 2015;65(9):967-72. 
28. Eddleston M, Dawson A, Karalliedde L, Dissanayake W, Hittarage A, Azher S, et al. Early management after self-poisoning with an organophosphorus or carbamate pesticide-a treatment protocol for junior doctors. Crit Care. 2004; 8(6):R391.

29. Vasantha M, Venkatesan P. Structural equation modeling of latent growth curves of weight gain among treated tuberculosis patients. PLoS One. 2014 9(3):1-8. https://doi.org/10.1371/journal.pone.0091152.

30. Wang J, Wang X. Structural equation modeling: applications using Mplus: John Wiley \& Sons; 2019

31. Jones $B L$, Nagin DS. A note on a Stata plugin for estimating group-based trajectory models. Sociol Methods Res. 2013;42(4):608-13.

32. Muthén B, Muthén BO. Statistical analysis with latent variables: Wiley new York; 2009.

33. Proust-Lima C, Letenneur L, Jacqmin-Gadda H. A nonlinear latent class model for joint analysis of multivariate longitudinal data and a binary outcome. Stat Med. 2007;26(10):2229-45.

34. Mirza SS, Wolters FJ, Swanson SA, Koudstaal PJ, Hofman A, Tiemeier H, et al. 10-year trajectories of depressive symptoms and risk of dementia: a population-based study. Lancet Psychiatry. 2016;3(7):628-35.

35. Axelrod YK, Diringer MN. Temperature management in acute neurologic disorders. Neurol Clin. 2008;26(2):585-603 xi.

36. Association $\mathrm{AH}$. Healthy and unhealthy blood pressure ranges [Web page]. American Heart Association; [Available from: https://www.heart.org/-/media/ files/health-topics/high-blood-pressure/hbp-rainbow-chart-english-pdfucm_499220.pdf.

37. Association AH. All about heart rate [Web page]. American Heart Association; [Available from: https://www.heart.org/.

38. Stedman T. Stedman's medical dictionary: Dalcassian publishing company; 1920.

39. Laupland KB. Fever in the critically ill medical patient. Crit Care Med. 2009; 37(7 Suppl):S273-8.

40. Mundhe SA, Birajdar SV, Chavan SS. The clinico-demographic study of morbidity and mortality in patients with organophosphate compound poisoning at tertiary care hospital in rural India. Int J Adv Med. 2017;4(3): 809.

41. Majidi M, Delirrad M, Banagozar Mohammadi A, Najaf Najafi M, Nekoueifard S, Alizadeh A, et al. Cholinesterase level in erythrocyte or serum: which is more predictive of the clinical outcome in patients with acute organophosphate poisoning? IJT. 2018;12(5):23-6.

42. Ahmed A, Ali L, Shehbaz L, Nasir S, Rizvi SRH, Zaeghum M, et al. Prevalence and characteristics of organophosphate poisoning at a tertiary care Centre in Karachi, Pakistan. Pak J Surg. 2016;32(4):269-73.

43. Tagwireyi D, Ball DE, Nhachi CF. Toxicoepidemiology in Zimbabwe: pesticide poisoning admissions to major hospitals. Clin Toxicol (Phila). 2006; 44(1):59-66.

44. Bjornaas MA, Jacobsen D, Haldorsen T, Ekeberg O. Mortality and causes of death after hospital-treated self-poisoning in Oslo: a 20-year follow-up. Clin Toxicol (Phila). 2009;47(2):116-23.

45. Ferrey AE, Geulayov G, Casey D, Wells C, Fuller A, Bankhead C, et al. Relative toxicity of mood stabilisers and antipsychotics: case fatality and fatal toxicity associated with self-poisoning. BMC Psychiatry. 2018;18(1):399.

46. Spiller HA, Ackerman JP, Spiller NE, Casavant MJ. Sex-and age-specific increases in suicide attempts by self-poisoning in the United States among youth and young adults from 2000 to 2018. J Pediatr. 2019;210:201-8.

47. Yu J-H, Weng Y-M, Chen K-F, Chen S-Y, Lin C-C. Triage vital signs predict inhospital mortality among emergency department patients with acute poisoning: a case control study. BMC Health Serv Res. 2012;12(1):262.

48. Lee YH, Oh YT, Lee WW, Ahn HC, Sohn YD, Ahn JY, et al. The association of alcohol consumption with patient survival after organophosphate poisoning: a multicenter retrospective study. Intern Emerg Med. 2017;12(4): 519-26.

49. Lee $\mathrm{JH}$, Lee $\mathrm{YH}$, Park YH, Kim YH, Hong CK, Cho KW, et al. The difference in C-reactive protein value between initial and 24 hours follow-up (D-CRP) data as a predictor of mortality in organophosphate poisoned patients. Clin Toxicol. 2013;51(1):29-34.

50. Moussa M, Mohamed S, Hilal M, Elnabi M, Zaki N. Predictive value of triage vital signs and conscious level for outcome evaluation in acutely organophosphate poisoned patients. Ain Shams J Forensic Med Clin Toxicol. 2018;31(2):33-40.
51. Kang C, Park IS, Kim DH, Kim SC, Jeong JH, Lee SH, et al. Red cell distribution width as a predictor of mortality in organophosphate insecticide poisoning. Am J Emerg Med. 2014;32(7):743-6.

52. Coskun R, Gundogan K, Sezgin GC, Topaloglu US, Hebbar G, Guven M, et al. A retrospective review of intensive care management of organophosphate insecticide poisoning: single center experience. Niger J Clin Pract. 2015; 18(5):644-50.

53. Talaie H, Owliaey H, Pajoumand A, Gholaminejad M, Mehrpour O. Temperature changes among organophosphate poisoned patients, TehranIran. DARU J Pharm Sci. 2012;20(1):52.

54. McArdle JJ. Latent variable modeling of differences and changes with longitudinal data. Annu Rev Psychol. 2009;60:577-605.

55. Eddleston M, Eyer P, Worek F, Mohamed F, Senarathna L, von Meyer $L$, et al Differences between organophosphorus insecticides in human selfpoisoning: a prospective cohort study. Lancet. 2005;366(9495):1452-9.

\section{Publisher's Note}

Springer Nature remains neutral with regard to jurisdictional claims in published maps and institutional affiliations.

Ready to submit your research? Choose BMC and benefit from:

- fast, convenient online submission

- thorough peer review by experienced researchers in your field

- rapid publication on acceptance

- support for research data, including large and complex data types

- gold Open Access which fosters wider collaboration and increased citations

- maximum visibility for your research: over $100 \mathrm{M}$ website views per year

At $\mathrm{BMC}$, research is always in progress.

Learn more biomedcentral.com/submissions 